\title{
PENENTUAN TEKNIK PERHITUNGAN KEBUTUHAN RUANG PARKIR HOTEL DI KOTA BEKASI
}

\author{
Handa Lesmana MT \\ Sekolah Tinggi Transportasi \\ Darat Jl. Raya Setu KM. 3,5 \\ Cibuntu Cibitung Bekasi \\ Tlp: (021) 8254640 \\ Fax: (021) 82608995 \\ info.p3m.sttd@gmail.com
}

\author{
Firga Ariani, SE, MMTr \\ Sekolah Tinggi Transportasi \\ Darat Jl. Raya Setu KM. 3,5 \\ Cibuntu Cibitung Bekasi \\ Tlp: (021) 8254640 \\ Fax: (021) 82608995
}

\author{
Rode Paulus GP, S.SiT, MT \\ Sekolah Tinggi Transportasi \\ Darat Jl. Raya Setu KM. 3,5 \\ Cibuntu Cibitung Bekasi \\ Tlp: (021) 8254640 \\ Fax: (021) 82608995
}

\author{
Fery Subekti, S.SiT, mt \\ Sekolah Tinggi Transportasi Darat \\ Jl. Raya Setu KM. 3,5 Cibuntu Cibitung Bekasi \\ Tlp: (021) 8254640 \\ Fax: (021) 82608995
}

\begin{abstract}
Bekasi City currently has a role as a supporter of the state capital of the East and pathway crossing from the West to the East of the island of Java and the west to the east of Indonesia. The hotel's existence should be supported by the provision of a good service facilities of course, with other supporting facilities such as parking spaces. If the provision of insufficient parking spaces will cause various problems in the smooth traffic system. Hotel parking space requirements necessary to have a standard function according to its land use we need some studies need parking standards for hotels in the city of Bekasi in accordance with the existing land use so that it can make a significant contribution in solving the problem of providing parking spaces and a hotel in Indonesia Bekasi City in particular.
\end{abstract}

Keywords: Calculation, Supplies, parking, Bekasi

\begin{abstract}
ABSTRAK
Saat ini Kota Bekasi memiliki peran sebagai pendukung ibukota negara dari sisi Timur maupun jalur perlintasan dari arah Barat ke Timur pulau Jawa dan dari pulau sebelah Barat ke sebelah Timur Indonesia. Keberadaan hotel tersebut harus ditunjang dengan penyediaan fasilitas pelayanan yang baik tentunya dengan fasilitas penunjang lainnya seperti ruang parkir. Apabila penyediaan ruang parkir kurang mencukupi akan menimbulkan berbagai masalah dalam kelancaran sistem lalu lintas. Kebutuhan ruang parkir hotel perlu memiliki standart menurut fungsi tata guna lahannya

perlu dilakukan suatu studi kebutuhan standar parkir untuk hotel di kawasan kota bekasi sesuai dengan tata guna lahan yang ada sehingga dapat menjadikan sumbangan yang berarti didalam memecahkan masalah penyediaan ruang parkir hotel di Indonesia dan Kota Bekasi khususnya.
\end{abstract}

\section{Kata Kunci : Perhitungan, Kebutuhan, Parkir, Bekasi}




\section{PENDAHULUAN}

\section{Latar Belakang}

Kota Bekasi memiliki dinamika yang tinggi dalam aktivitas segala bidang. Salah satu aspeknya adalah berupa tingkat perjalanan yang tinggi di bekasi. Hal ini terkait dengan peran Kota Bekasi yang bergerak sebagai kota jasa, industri, perumahan permukiman, dan perdagangan. Terlebih lagi secara posisi regional, Kota Bekasi memiliki peran sebagai pendukung ibukota negara dari sisi Timur maupun jalur perlintasan dari arah Barat ke Timur pulau Jawa dan dari pulau sebelah Barat ke sebelah Timur Indonesia.

Di kota Bekasi sebagai penyangga ibu kota Negara dan kota jasa, keberadaan prasarana hotel menjadi sangat penting dikarenakan berbagai macam kegiatan dan aktivitas terpusat di Kota ini. Keberadaan hotel tersebut harus ditunjang dengan penyediaan fasilitas pelayanan yang baik tentunya dengan fasilitas penunjang lainnya seperti ruang parkir. Apabila penyediaan ruang parkir kurang mencukupi akan menimbulkan berbagai masalah dalam kelancaran sistem lalu lintas. Kebutuhan ruang parkir hotel perlu memiliki standart menurut fungsi tata gunalahannya. Sebagai contoh, Amerika Serikat, Inggris dan Australia telah melakukan studi standar kebutuhan parkir sedangkan untuk Indonesia beberapa studi pendahuluan telah dilakukan, namun belum terdapat teknik perhitungan kebutuhan ruang parkir. Untuk itu maka perlu dilakukan suatu studi kebutuhan standar parkir untuk hotel di kawasan kota bekasi sesuai dengan tata guna lahan yang ada sehingga dapat menjadikan sumbangan yang berarti didalam memecahkan masalah penyediaan ruang parkir hotel di Indonesia dan Kota Bekasi khususnya.

\section{Tujuan}

Tujuan dari dilakukannya penelitian Kajian Penentuan Teknik Perhitungan Kebutuhan Ruang Parkir Hotel Di Kota Bekasi ini adalah sebagai berikut:

1. Mengetahui teknik perhitungan kebutuhan parkir hotel dengan beberapa metode.

2. Melakukan perbandingan hasil analisa kebutuhan dari berbagai metode

3. Menghasilkan teknik perhitungan kebutuhan parkir hotel yang sesuai dengan penggunaan lahan dan kebutuhan sesungguhnya. 


\section{PEMBAHASAN}

\section{Pengumpulan Data}

Metode pengumpulan data meliputi pengumpulan berbagai informasi berkaitan dengan data yang diperlukan untuk menganalisis permasalahan pada daerah penelitian. Metode yang digunakan dalam pengumpulan data adalah:

11.Pengumpulan Data Primer

Pengumpulan Data primer didapatkan dengan cara melakukan survei langsung di lapangan, data Primer tersebut yaitu:

a. Data Patroli Parkir

Survey ini digunakan untuk mengetahui kendaraan yang masuk dan keluar area parkir dan waktu yang dibutuhkan kendaraan untuk parkir, Sehingga diketahui besarnya pergantian parkir dan durasi parkir.

b. Data Volume Parkir

Survey ini dilakukan bertujuan untuk mengetahui jumlah keseluruhan kendaraan yang menggunakan fasilitas parkir per satuan waktu selama 13 jam dengan interval waktu 15 menit.

c. Data Inventarisasi Parkir

Survai ini bertujuan untuk melakukan pengukuran terhadap kawasan parkir yang dijadikan bahan penelitian. Survai dilakukan pada malam hari untuk memudahkan dalam pengukuran dan menghindari arus lalu lintas. Target data atau output yang dihasilkan adalah :

1)Lokasi parkir;

2)Lebar lokasi parkir

3)Panjang lokasi parkir;

4)Kapasitas parkir;

5)Peruntukan parkir.

Alat yang digunakan dalam survai inventaris adalah

1) Walking measure;

2) Rol meter;

3) Alat tulis;

4) Formulir.

d. Pengumpulan Data Sekunder 
Metode pengumpulan data ini dilakukan dengan cara memperoleh data dari instansi - instansi terkait. Data yang didapat tersebut adalah jumlah kamar hotel dan jumlah SRP parkir.

\section{METODE ANALISIS}

Adapun analisis yang digunakan dalam studi ini adalah :

1.Analisis Kebutuhan Parkir

Analisa kebutuhan parkir ini dilakukan dengan cara mencari nilai dari karakterisik parkir eksisting antara lain:

a. Akumulasi Parkir

Akumulasi $\sqcap E i \sqcap E i \sqcap X$

Sumber :Munawar, A (2015)

Keterangan :

Ei: $\sum$ kendaraan yang masuk lokasi parkir

Ex: $\sum$ kendaraan yang keluar lokasi parkir

$\mathrm{X}: \sum$ kendaraan yang telah berada di lokasi parkir sebelum pengamatan dilakukan

b.Durasi Parkir

Rentang waktu parkir dari sebuah kendaraan ini dapat dihitung dengan menggunakan rumus:

$$
\text { Durasi }=\text { Extime }- \text { Entime }
$$

Sumber:Munawar, A (2015)

Keterangan :

Extime :waktu saat kendaraan masuk lokasi parkir

Entime :waktu saat kendaraan keluar lokasi parkir

c.Volume Parkir

Jumlah keseluruhan kendaraan yang menggunakan fasilitas parkir per satuan waktu selama jam operasi dengan interval 15 menit.

2.Kapasitas Rencana Parkir Off Street (Layout Parkir) Kapasitas Rencana Off Street ini nantinya akan menggambarkan tentang SRP yang dibutuhkan yang sudah disesuaikan dengan luas lahan yang ada agar kebutuhan parkir dapat terpenuhi secara optimal dan efisien. 


\section{Analisis Data}

\section{A. METODE TURN OVER}

Metode turn over merupakan metode yang digunakan dalam perhitungan parkir dengan menggunakan teori antrian. Berikut ini merupakan hasil dari perhitungan kebutuhan parkir dengan Metode Turn Over.

Analisis data dengan menggunakan Metode Turn Over

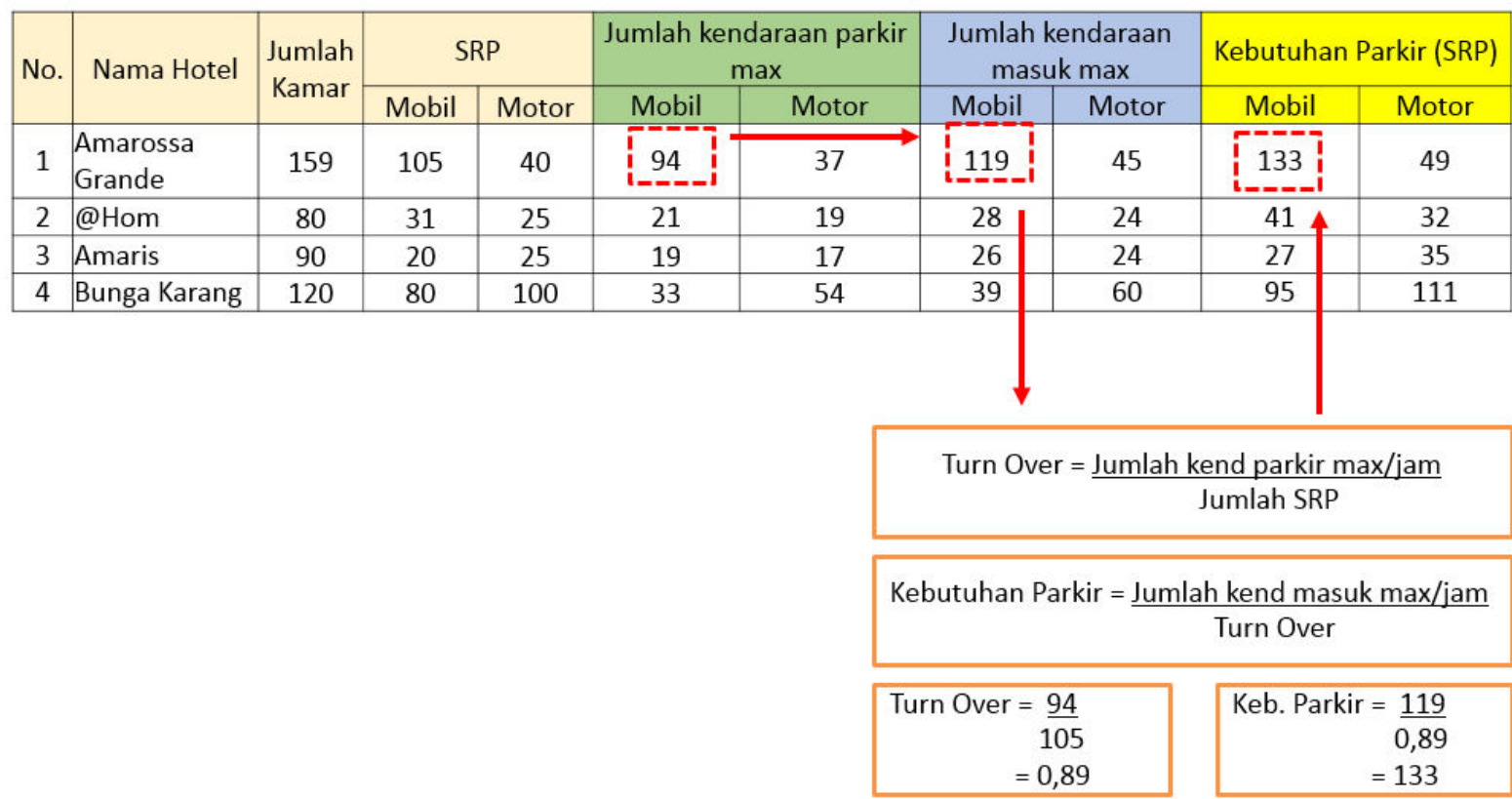

Berdasarkan tabel diatas dapat diketahui bahwa hasil perhitungan kebutuhan parkir (SRP) dengan Metode Turn Over pada hotel Amarrosa Grande untuk mobil membutuhkan sebanyak 133 SRP dan motor membutuhkan sebanyak 49 SRP. Untuk Hotel @ Hom memiliki kebutuhan parkir mobil sebanyak 41 SRP dan motor sebanyak 32 SRP. Sedangkan untuk hotel bintang 2 Amaris memiliki kebutuhan parkir Mobil sebanyak 27 SRP dan motor sebanyak 35 SRP. Untuk hotel bintang 2 Bunga Karang memiliki kebutuhan parkir Mobil sebanyak 95 SRP dan Motor sebanyak 111 SRP. 


\section{B.METODE S.K DIRJEN I}

Teknik analisis kebutuhan parkir dengan menggunakan metode S.K. Dirjen I adalah dengan melihat dengan banyaknya kamar yang tersedia dan tarif yang digunakan seperti yang tercantum dalam tabel dibawah ini.

\begin{tabular}{|c|c|c|c|c|c|c|c|c|c|c|}
\hline \multicolumn{2}{|c|}{ Jumlah Kamar (buah) } & 100 & 150 & 200 & 250 & 350 & 400 & 550 & 550 & 600 \\
\hline \multirow{4}{*}{$\begin{array}{l}\text { Tarip } \\
\text { Standart } \\
(\$)\end{array}$} & $<100$ & 154 & 155 & 156 & 158 & 161 & 162 & 165 & 166 & 167 \\
\hline & $100-150$ & 300 & 450 & 476 & 477 & 480 & 481 & 484 & 485 & 487 \\
\hline & $150-200$ & 300 & 450 & 600 & 798 & 799 & 800 & 803 & 804 & 806 \\
\hline & $200-250$ & 300 & 450 & 600 & 900 & 1050 & 1119 & 1122 & 1124 & 1425 \\
\hline
\end{tabular}

Dengan memasukkan karakteristik hasil survey yang dilakukan pada 4 hotel diperoleh hasil sebagai berikut :

Analisis data dengan menggunakan Metode SK. Dirjen I

\begin{tabular}{|c|l|c|c|c|c|c|c|}
\hline \multirow{2}{*}{ No. } & \multirow{2}{*}{ Nama Hotel } & \multirow{2}{*}{ Jumlah Kamar } & \multicolumn{2}{|c|}{ SRP } & \multirow{2}{*}{ SRP TOTAL } & \multicolumn{2}{|c|}{ SK. DIRJEN } \\
\cline { 4 - 7 } & & & Mobil & Motor & & Kriteria Harga Hotel (\$) & Kebutuhan Parkir (SRP) \\
\hline 1 & Amarossa Grande & 159 & 105 & 40 & 145 & $100-150$ & 476 \\
\hline 2 & @Hom & 80 & 31 & 25 & 56 & $<100$ & 154 \\
\hline 3 & Amaris & 90 & 20 & 25 & 45 & $<100$ & 154 \\
\hline 4 & Bunga Karang & 120 & 80 & 100 & 180 & $<100$ & 155 \\
\hline
\end{tabular}

Berdasarkan hasil analisis seperti yang tercantum dalam tabel diatas diketahui bahwa Hotel Amarosa Grande memiliki kriteria harga hotel dengan range $\$ 100$ - \$150 dan memiliki kebutuhan parkir sebanyak 476 SRP. Untuk hotel @ Hom memiliki kriteria harga hotel dengan range $<\$ 100$ dengan kebutuhan parkir sebanyak 154 SRP. Hotel Amaris memiliki kriteria harga hotel dengan range $<\$ 100$ dengan kebutuhan parkir sebanyak 154 SRP. Sedangkan untuk hotel Bunga Karang memiliki kriteria harga hotel dengan range $<\$ 100$ dengan kebutuhan parkir sebanyak 155 SRP. 


\section{C.METODE S.K DIRJEN II}

\section{UKURAN KEBUTUHAN RUANG PARKIR}

\begin{tabular}{|l|l|c|}
\hline Peruntukan & $\begin{array}{l}\text { Satuan } \\
\text { (SRP untuk mobil penumpang) }\end{array}$ & $\begin{array}{c}\text { Kebutuhan } \\
\text { Ruang Parkir }\end{array}$ \\
\hline $\begin{array}{l}\text { Pusat Perdagangan } \\
\text { - Pertokoan }\end{array}$ & SRP / $100 \mathrm{~m}^{2}$ luas lantai efektif \\
- Pasar Swalayan & SRP / $100 \mathrm{~m}^{2}$ luas lantai efektif & $3,5-7,5$ \\
Pusat Perkantoran & SRP / $100 \mathrm{~m}^{2}$ luas lantai efektif & $3,5-7,5$ \\
- Pelayanan bukan umum & SRP / 100 $\mathrm{m}^{2}$ luas lantai & \\
- Pelayanan umum & SRP / $100 \mathrm{~m}^{2}$ luas lantai & $1,5-3,5$ \\
Sekolah & SRP / mahasiswa & \\
Hotel/Tempat Penginapan & SRP / kamar & $0,7-1,0$ \\
Rumah Sakit & SRP / tempat tidur & $0,2-1,0$ \\
Bioskop & SRP / tempat duduk & $0,2-1,3$ \\
\end{tabular}

Sumber : Naasra 1988

Analisis data dengan menggunakan Metode SK. Dirjen II

\begin{tabular}{|c|c|c|c|c|c|c|c|c|c|c|c|c|c|}
\hline \multirow{2}{*}{ No. } & \multirow{2}{*}{ Nama Hotel } & \multirow{2}{*}{$\begin{array}{l}\text { Jumlah } \\
\text { Kamar }\end{array}$} & \multirow{2}{*}{$\begin{array}{c}\text { SRP } \\
\text { Mobil }\end{array}$} & \multicolumn{9}{|c|}{ Kebutuhan Parkir (SRP) Mobil } & \multirow{2}{*}{$\begin{array}{l}\text { Kebutuhan } \\
\text { Parkir (SRP) }\end{array}$} \\
\hline & & & & 0.2 & 0.3 & 0.4 & 0.5 & 0.6 & 0.7 & 0.8 & 0.9 & 1 & \\
\hline 1 & AmarossaGrande & 159 & 105 & 32 & 48 & 64 & 80 & 95 & 111 & 127 & 143 & 159 & 111 \\
\hline 2 & $@$ Hom & 80 & 31 & 16 & 24 & 32 & 40 & 48 & 56 & 64 & 72 & 80 & 32 \\
\hline 3 & Amaris & 90 & 20 & 18 & 27 & 36 & 45 & 54 & 63 & 72 & 81 & 90 & 27 \\
\hline 4 & Bunga Karang & 120 & 80 & 24 & 36 & 48 & 60 & 72 & 84 & 96 & 108 & 120 & 84 \\
\hline
\end{tabular}

Berdasarkan tabel diatas dapat diketahui bahwa kebutuhan parkir untuk Hotel Amarossa Grande adalah 111 SRP. Untuk hotel @Hom memiliki kebutuhan parkir sebanyak 32 SRP. Hotel Amaris memiliki kebutuhan parkir sebanyak 27 SRP dan Hotel Bunga Karang memiliki kebutuhan parkir sebanyak 84 SRP. 


\section{D.PERBANDINGAN ANTARA HASIL PERHITUNGAN PARKIR DENGAN JUMLAH PARKIR YANG DISEDIAKAN}

Tabel Perbandingan Hasil Perhitungan dengan Metode Turn Over

\begin{tabular}{lcccccccc}
\hline & & & \multicolumn{3}{c}{ Kebutuhan } & \multicolumn{4}{c}{$\%$} \\
No. Nama Hotel & Jumlah & SRP (Eksisting) & Parkir (SRP) & Perbedaan & \% Perbedaan \\
& Kamar & Mobil & Motor & Mobil & Motor & Mobil Motor & rata-rata \\
& 159 & 105 & 40 & 133 & 49 & $21 \%$ & $18 \%$ & \\
1 Amarossa Grande & 80 & 31 & 25 & 41 & 32 & $25 \%$ & $21 \%$ & \\
2 @Hom & 90 & 20 & 25 & 27 & 35 & $27 \%$ & $29 \%$ & $21 \%$ \\
3 Amaris & 120 & 80 & 100 & 95 & 111 & $15 \%$ & $10 \%$ & 2 \\
4 Bunga Karang & & & & & & & & \\
\hline
\end{tabular}

Berdasarkan tabel diatas dapat diketahui bahwa perbedaan rata- rata antara hasil perhitungan parkir dengan Metode Turn Over dengan jumlah parkir yang disediakan adalah sebesar $21 \%$.

Tabel Perbandingan Hasil Perhitungan dengan Metode S.K Dirjen I

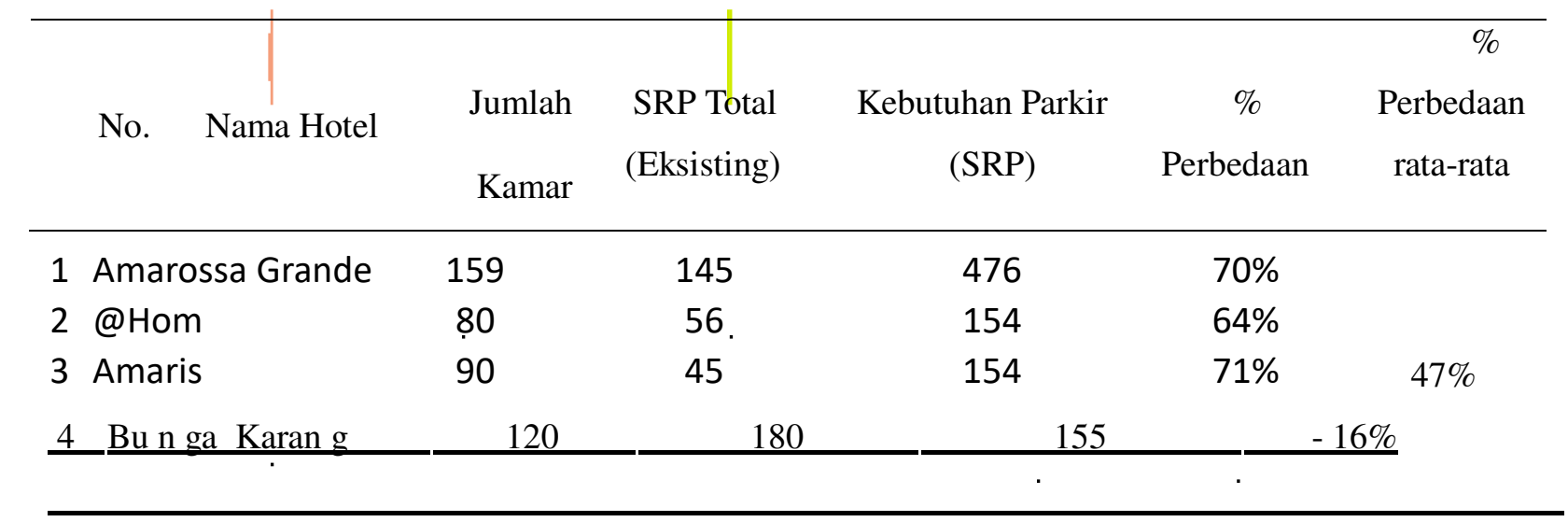

Berdasarkan tabel diatas dapat diketahui bahwa perbedaan rata- rata antara hasil perhitungan parkir dengan Metode S.K. Dirjen I dengan jumlah parkir yang disediakan adalah sebesar $47 \%$. 
Tabel Perbandingan Hasil Perhitungan dengan Metode S.K Dirjen II

\begin{tabular}{lccccc} 
No. Nama Hotel & $\begin{array}{c}\text { Jumlah } \\
\text { Kamar }\end{array}$ & $\begin{array}{c}\text { SRP Total } \\
\text { (Eksisting) }\end{array}$ & $\begin{array}{c}\text { Kebutuhan Parkir } \\
\text { (SRP) }\end{array}$ & $\begin{array}{c}\% \\
\text { Perbedaan }\end{array}$ & $\begin{array}{c}\text { Perbedaan } \\
\text { rata-rata }\end{array}$ \\
1 Amarossa Grande & 159 & 145 & 476 & $70 \%$ & \\
2 @Hom & 80 & 56 & 154 & $64 \%$ & $47 \%$ \\
3 Amaris & 90 & 45 & 154 & $71 \%$ & $-16 \%$ \\
\hline
\end{tabular}

Berdasarkan tabel diatas dapat diketahui bahwa perbedaan rata- rata antara hasil perhitungan parkir dengan Metode S.K. Dirjen II dengan jumlah parkir yang disediakan adalah sebesar $10 \%$. Untuk mempermudah dalam proses perbandingan hasil analisis akan disajikan dalam bentuk grafik seperti dibawah ini :

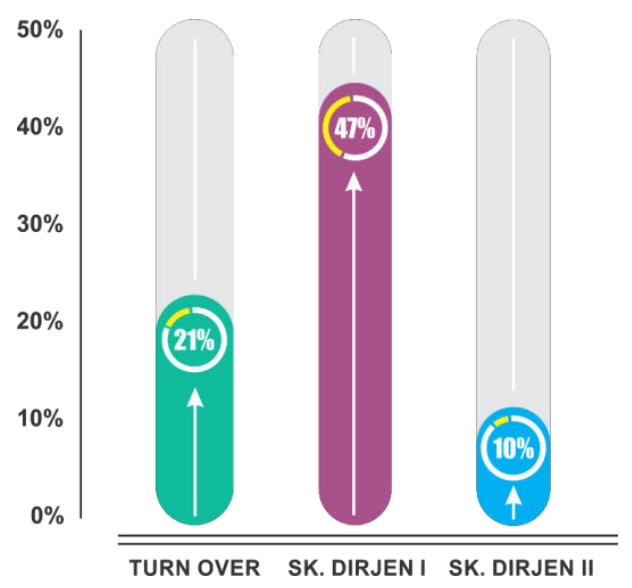

Gambar Grafik Perbandingan Analisis antar Metode

Dengan melihat grafik diatas dapat diketahui bahwa Metode dengan tingkat perbedaan terendah antara hasil analisis dengan jumlah parkir yang disediakan adalah Metode S.K. Dirjen dengan tingkat perbedaan sebanyak 10\%. Hal ini dapat disimpulkan bahwa teknik perhitungan yang paling baik adalah dengan Metode S.K. Dirjen II. 


\section{KESIMPULAN}

Berdasarkan hasil analisis yang telah dilakukan pada bab sebelumnya, dapat disimpulkan bahwa :

- Untuk Hotel Amarossa Grande (Bintang 4) metode perhitungan kebutuhan parkir yang mendekati adalah SK.Dirjen II;

- Untuk Hotel @ HOM (Bintang 3) metode perhitungan kebutuhan parkir yang mendekati adalah SK.Dirjen II;

- Untuk Hotel Amaris (Bintang 2) metode perhitungan kebutuhan parkir yang mendekati adalah SK. Dirjen II;

- Untuk Hotel Bunga Karang (Bintang 1) metode perhitungan kebutuhan parkir yang mendekati adalah SK. Dirjen II.

\section{SARAN}

Perlunya dilakukan kajian lebih lanjut dengan jumlah dan jenis hotel yang lebih banyak.

\section{DAFTAR PUSTAKA}

(2009) Undang-undang Nomor 22 Tahun 2009 Tentang Lalu Lintas dan Angkutan Jalan, Direktorat Jenderal Perhubungan Darat, Jakarta (1996) Keputusan Direktur Jenderal Perhubungan Darat Nomor 272 Tahun 1996 Tentang Pedoman Teknis Penyelenggaraan Fasilitas Parkir

Tamin, O.Z. (2008) Perencanaan, Permodelan, dan Rekayasa Transportasi, Bandung

A, Munawar (2015) Manajemen Rekayasa Lalu Lintas 